\title{
FORMAÇÃO PEDAGÓGICA DE PROFESSORES E AVALIAÇÃO DA APRENDIZAGEM NA UNIVERSIDADE: CONTRIBUIÇÕES DA PESQUISA-AÇÃO
}

\author{
PEDAGOGICAL TRAINING OF PROFESSORS AND ASSESSMENT OF \\ LEARNING AT UNIVERSITY: CONTRIBUTIONS OF ACTION \\ RESEARCH
}

\author{
Maria Iolanda Fontana \\ Doutora em Educação pela Universidade Tuiuti do Paraná (UTP) \\ Professora Adjunta da Universidade Tuiuti do Paraná (UTP) \\ maria.iolanda.fontana@gmail.com
}

Resumo: Este trabalho tem por objetivo discutir a formação pedagógica na universidade, mediada pela pesquisa-ação, e suas repercussões na constituição de saberes sobre práticas avaliativas de concepção formativa. Problematiza-se a ausência de formação pedagógica para superar o tradicional empirismo que marca a prática docente na educação superior, em especial na dimensão da avaliação da aprendizagem. Defende-se a pesquisa-ação no processo formativo de professores da universidade, considerando seu potencial metodológico para a problematização e ação coletiva, consciente e criticamente comprometida com a melhora da prática pedagógica e da aprendizagem discente. Apresentam-se dados qualitativos da pesquisa-ação desenvolvida com docentes da Universidade Tuiuti do Paraná e os seus reflexos nas práticas de avaliação da aprendizagem. Este processo formativo repercutiu contribuições ao desenvolvimento profissional dos docentes, para refletirem e transformarem suas práticas avaliativas, reconhecendo seu papel formativo e democratizador, ou seja, subsidiou decisões teórico-metodológicas e investigativas sobre como avaliar para qualificar a prática docente e as aprendizagens dos estudantes.

Palavras-chave: Avaliação da aprendizagem. Formação pedagógica. Pedagogia universitária. Pesquisaação.

\begin{abstract}
This paper aims to discuss pedagogical training at the university, mediated by action research, and its repercussions on the constitution of knowledge about evaluative practices of formative conception. The absence of pedagogical training to overcome the traditional empiricism that marks the teaching practice in higher education is problematized, especially in the dimension of learning assessment. Action research is advocated in the university teachers' training process, considering its methodological potential for problematizing and collective action, consciously and critically committed to improving pedagogical practice and student learning. Qualitative data from the action research developed with professors from the Universidade Tuiuti do Paraná and its reflexes in the learning evaluation practices are presented. This formative process reflected contributions to the professional development of teachers, to reflect and transform their evaluative practices, recognizing their formative and democratizing role, that is, it supported theoretical-methodological and investigative decisions on how to evaluate to qualify the teaching practice and the students' learning.
\end{abstract}

Keywords: Learning assessment. Pedagogical training. University pedagogy. Action research. Pedagogical practice.

Para citar - (ABNT NBR 6023:2018)

FONTANA, Maria Iolanda. Formação pedagógica de professores e avaliação da aprendizagem na universidade contribuições da pesquisa-ação. Eccos - Revista Cientifica, São Paulo, n. 55, p. 1-14, e18873, out./dez. 2020. Disponível em: https://doi.org/10.5585/eccos.n55.18873. 


\section{Introdução}

Compreende-se a qualidade da ação formativa na educação superior pautada na indissociabilidade entre ensino, pesquisa e extensão, consolidada na formação humana para a resolução de problemas sociais e intervenção ética às crises contemporâneas na sociedade capitalista. Para tanto, se faz imperativo que, neste espaço, se estabeleçam relações e compromissos entre a docência na graduação e pós-graduação, aliadas criticamente, para fins de democratizar o ensino e a pesquisa na educação superior. Não é incomum a pesquisa na universidade, principalmente em nível stricto sensu, ocorrer apartada da atividade de ensino e dos problemas que marcam a atividade docente na graduação. A docência na universidade requer articulação tanto de saberes da área profissional, quanto os pedagógicos, fundamentados na teoria crítica, comprometida com a construção do conhecimento e da aprendizagem de qualidade social. Para tanto, é imprescindível ocorrerem, em nível institucional, processos de formação docente, de caráter investigativo, sobre a prática pedagógica, pois quando os professores pesquisam, produzem novos conhecimentos e, assim, estabelecem novos compromissos de cunho crítico para inovar e aperfeiçoar um ensino coeso às demandas do movimento histórico da educação, ciência e sociedade.

A pesquisa-ação na universidade sobre a prática pedagógica pode ser uma relevante alternativa para articular pesquisa e ensino, teoria e prática, graduação e pós-graduação e, de tal modo, promover a cientificidade da docência, considerando que esta concepção de pesquisa "é, ao mesmo tempo, ferramenta de mudança e de formação" (DIONNE, 2007, p.21). É nesta dimensão que se discute neste artigo a formação pedagógica de professores, mediada pela pesquisa-ação, para investigar e resolver os problemas da prática pedagógica, especificamente sobre a avaliação da aprendizagem discente, considerando sua relevância para o processo de democratização das aprendizagens e do conhecimento na educação superior.

Problemas como a evasão, repetência e o baixo desempenho de estudantes da educação superior, revelados nos resultados de exames de larga escala, têm suscitado questionamentos sobre como a universidade e os docentes concebem o ensino e praticam a avaliação da aprendizagem. Segundo Garcia (2009, p. 211), é necessário “avançar nas discussões sobre avaliação e formação de professores", sobre questões relativas às escolhas e expectativas de aprendizagem explicitadas, ou não, em suas práticas avaliativas. A escassa produção do conhecimento sobre a temática "avaliação e formação continuada de professores" é constatada na revisão bibliográfica sobre avaliação das aprendizagens no Brasil, realizada por Boldarine, Barbosa e Annibal (2017). A pesquisa encontra apenas 10 artigos, dentre 171 localizados em 
11 periódicos de circulação nacional, no período de 2010 a 2014. Os autores inferem como resultado comum que "os espaços de formação são utilizados para pensar como melhorar os índices e não, necessariamente, repensar a maneira como são conduzidos os processos de ensino e aprendizagem dos estudantes" (BOLDARINE; BARBOSA; ANNIBAL, 2017, p. 174).

O estado da arte realizado por Poltronieri e Calderón (2015) a respeito da avaliação da aprendizagem na educação superior, divulgada na revista Estudos em Avaliação Educacional (EAE), desde sua criação em 1990 até 2010, não destaca entre as temáticas identificadas a formação de professores e a avaliação, havendo apenas um artigo que aborda a formação de professores do curso de Enfermagem para superar práticas avaliativas que pouco contribuem para a formação profissional do acadêmico.

Estes indicativos expressam a necessidade de maior atenção ao processo de formação pedagógica de docentes da educação superior, para refletir novas práticas de ensinar e avaliar a aprendizagem, de modo a superar práticas avaliativas de caráter seletivo que exclui o estudante do processo constante de aprendizagem e de seu desenvolvimento. Defende-se a concepção formativa de avaliação da aprendizagem, de característica investigativa e diagnóstica, pois temse como premissa que todos, mesmo com experiências escolares e ritmos diferentes, são capazes de aprender, desde que assegurada a mediação didática pertinente às suas necessidades. Nesse contexto, a avaliação formativa assume a dimensão democrática do trabalho educativo.

Com o objetivo de fomentar a reflexão e investigação sobre as práticas de avaliar na perspectiva formativa da aprendizagem, discutem-se, neste artigo, as contribuições do projeto de pesquisa-ação, coordenado pelo Núcleo de Apoio Docente, vinculado ao Programa de PósGraduação em Educação e a Pró-Reitoria Acadêmica, da Universidade Tuiuti do Paraná. O projeto de pesquisa-ação iniciou no ano de 2017, com o objetivo de promover a formação pedagógica por meio da investigação compartilhada entre os docentes de diferentes cursos da graduação e do Programa de Pós-Graduação stricto sensu em Educação, com foco na relação entre inovações na prática pedagógica e aprendizagem discente. $\mathrm{O}$ projeto de pesquisa-ação envolveu os professores, na identificação das necessidades formativas e de ações de intervenção pedagógica para melhoria da aprendizagem discente. Neste artigo, trata-se dos processos da formação pedagógica, intervenções e resultados alcançados em práticas da avaliação da aprendizagem no contexto da pesquisa-ação.

A estrutura do texto inicia com a discussão sobre a pedagogia universitária de perspectiva emancipatória e a formação pedagógica de professores para desdobramentos em práticas de avaliação da aprendizagem de concepção formativa. Na sequência, abordam-se as 
contribuições da pesquisa-ação na formação pedagógica dos docentes da referida universidade, com vistas à reflexão e inovação da prática de avaliação da aprendizagem.

\section{Formação pedagógica de professores para prática de avaliação da aprendizagem formativa na educação superior}

É consenso entre autores que investigam a docência na educação superior, assim como aqueles que investigam a avaliação da aprendizagem neste nível de ensino, a constatação da necessidade de formação pedagógica dos docentes como fator imprescindível para o desenvolvimento do campo profissional e social. Significa a demanda por processos de formação pedagógica em âmbito institucional, para a formação fundamentada na teoria pedagógica crítica comprometida com o processo de formação humana e com a emancipação intelectual, científica e cultural, discente e docente. Existe um campo científico "específico de saberes que precisam ser mobilizados para que a educação superior alcance sua dimensão política, social e cognitiva, a qual se constitui na pedagogia universitária que caracteriza o docente como um profissional professor" (CUNHA, 2018, p. 10).

A pedagogia universitária problematiza o senso comum e o empirismo no trabalho docente, desprovido de formação pedagógica e defende a necessária relação entre o conhecimento de um campo disciplinar específico de formação e o conhecimento do campo didático-pedagógico, isto é, a dupla competência do saber disciplinar e do saber pedagógico na educação superior (CUNHA, 2018; VEIGA, 2011; FRANCO, 2013; PIMENTA; ANASTASIOU, 2005). O intento é o desenvolvimento profissional do docente da educação superior para realizar a qualidade social de sua profissionalidade. Ensinar com qualidade social na educação superior requer que o ensino, pesquisa e extensão se materializem no espaço universitário e na docência, a fim de consolidar a condição humana na apropriação e uso do saber crítico, ético e político, em práticas sociais do mundo do trabalho e nas relações interpessoais. Para isso, torna-se imperativo equacionar os modos como os professores da universidade aprendem, ensinam e se desenvolvem profissionalmente. O desenvolvimento profissional é entendido "como um processo a longo prazo, no qual se integram diferentes tipos de oportunidades e experiências, planificadas sistematicamente para promover o crescimento e desenvolvimento do docente" (MARCELO, 2009, p. 7).

Segundo explica Cunha (2018), os aportes da teoria da educação são fundamentais no processo de formação do docente, incluindo a autocompreensão dos processos subjetivos da construção da professoralidade docente como ação "complexa que requer saberes disciplinares, culturais, afetivos, éticos, metodológicos, psicológicos, sociológicos e políticos" (CUNHA, 
2018, p. 10). Tal proposta demanda transformações em relação à forte presença do pensamento positivista e pragmático na formação e prática docente. Como assinala Veiga (2011, p. 456), a docência na Educação Superior foi influenciada pela concepção disciplinar fragmentada, que separa a teoria da prática, o saber do fazer, o sujeito do objeto e, portanto, não aborda a complexidade do processo didático em seus pilares: ensinar, aprender, pesquisar e avaliar.

Neste campo, a literatura educacional sobre a educação superior aponta a lacuna de formação pedagógica, para além da didática instrumental, que orienta para o uso de técnicas e recursos, visando o controle do ensino e da avaliação da aprendizagem. A prática profissional da docência exige uma fundamentação teórica explícita, formulada e trabalhada com base no conhecimento da realidade concreta. "A prática é ponto de partida e de chegada do processo de formação" (VEIGA, 2008, p. 16).

A legislação, assim como as orientações para a docência na educação superior, tem enfatizado a necessidade da transferência do foco do trabalho docente no ensino em relação ao conteúdo, metodologias e avaliação para o foco na aprendizagem discente, o que significa organizar o processo de ensino para que os estudantes possam ter acesso ao conhecimento, desenvolver orientações e recursos que os ajudem acompanhar o seu desenvolvimento e aprendizagem (ZABALZA, 2004, p. 128). Para o autor, a profissionalização do docente na universidade requer levar em consideração não apenas processos vinculados ao ensinar, como também ao aprender. Ou seja, significa que, para ser um bom docente, é necessário vincular as atividades ao processo de aprendizagem dos estudantes (ZABALZA, 2004, p. 191).

O reconhecimento do perfil dos estudantes que adentram na educação superior, suas carências e potencialidades em constante movimento, suscita alteração de tradicionais formas de ensinar avaliar e aprender. Os baixos índices de desempenho de estudantes da educação superior revelam descompassos de ordem curricular, de ensino e de avaliação da aprendizagem. Para Cunha (2018, p. 9), é “emergente uma educação que prepare as novas gerações para a imprevisibilidade e para a capacidade de continuar aprendendo", ou seja, superar a exigência da memória e da resposta única e valorizar a dúvida e a formulação de perguntas para estruturar problemas investigativos. "O processo de formação deve ser compatível com o contexto social, político e econômico, comprometido - técnica e politicamente - com a construção de perspectivas emergentes e emancipatórias que se alinhem com a inclusão social" (VEIGA, 2008, p. 16).

Trata-se de inovar o ensino e avançar para uma perspectiva orgânica no processo de concepção, desenvolvimento e avaliação da experiência pedagógica na educação superior, especialmente em relação à apreensão das decisões pedagógicas que acompanham todo o 
processo de ensinar e aprender. Isso "requer uma forma de pacto entre professor e alunos e desses entre si, no que se refere às regras do trabalho pedagógico, incluindo sua avaliação" (CUNHA, 2016, p. 98-99).

Por revelar a qualidade da realidade do ensino e da aprendizagem, a avaliação se expressa efetivamente como elemento essencial da prática pedagógica de perspectiva emancipatória, pois efetiva sua finalidade epistemológica, isto é, "subsidiar decisões para promover aprendizagens satisfatórias para todos os estudantes" (LUCKESI, 2018, p. 160).

$\mathrm{O}$ ato de avaliar a aprendizagem como investigação da qualidade da realidade requer planejamento para a execução de seus passos metodológicos, que, segundo Luckesi (2018, p. 134), se não forem realizados, inviabilizam a efetiva avaliação. São eles: 1 . Configurar o objeto da investigação avaliativa; 2. Coletar os dados e descrever o objeto do ato avaliativo; e, por último, 3. Estabelecer qualidade da realidade investigada, por meio da comparação de sua descritiva com um critério de qualidade previamente estabelecido, como satisfatório ou insatisfatório. Para o autor, o ato avaliativo se encerra nesse ponto, e daí em diante caberá ao gestor da ação "as decisões a respeito de como servir-se do conhecimento a respeito da qualidade da realidade produzida pela investigação avaliativa" (LUCKESI, 2018, p. 55). A atribuição de qualidade ao objeto de investigação não basta ser um "padrão corriqueiro, de senso comum, mas o padrão efetivo e necessário da qualidade, segundo o currículo e o plano de ensino estabelecidos" (LUCKESI, 2018, p. 152).

Portanto, é necessária a competência pedagógica do docente, ou seja, o conhecimento de parâmetros teórico-metodológicos consistentes da avaliação para que ela seja efetivamente uma investigação planejada e coerente com seus princípios epistemológicos e com as finalidades formativas da aprendizagem na educação superior. Significa ser necessário ao docente compreender a gestão formativa da avaliação, ou seja, a tomada de decisão a respeito dos conhecimentos obtidos sobre a qualidade da realidade investigada, que esclarece Luckesi (2018, p. 174), conduz a ação para atingir o resultado desejado de nível satisfatório.

A abordagem formativa da avaliação da aprendizagem refere-se ao uso diagnóstico dos resultados da investigação, cujo fim é subsidiar a ação docente para que todos os estudantes aprendam, e, deste modo, se contrapõe à avaliação seletiva e excludente. É imperioso fortalecer e "aprofundar a ideia de avaliar para aprender para enfrentar as questões mais prementes e urgentes da educação contemporânea" (FERNANDES, 2006, p. 43).

A teoria da avaliação da aprendizagem de concepção formativa é complexa e mais rica em relação à visão de avaliação de princípios tecnicistas, que é centrada em objetivos comportamentais e em resultados obtidos após um dado período de ensino. Segundo Fernandes 
(2006, p. 23), a concepção formativa abrange "uma avaliação interativa, centrada nos processos cognitivos dos alunos e associada aos processos de feedback, de regulação, de auto avaliação e de autorregulação das aprendizagens". O autor elucida que o desenvolvimento desta concepção está ancorado em teorias de aprendizagem e de currículo e apresenta variações mais ou menos elaboradas de uma avaliação formativa inspirada em concepções cognitivistas, construtivistas e/ou socioculturais da aprendizagem. No entanto, nenhuma delas tem a ver com a avaliação formativa de inspiração behaviorista, cuja característica é mais restrita e limitada à verificação da consecução de objetivos comportamentais, prática considerada a mais predominante nos sistemas educativos, segundo a visão de autores que pesquisam o tema (FERNANDES, 2006, p. 25).

Algumas causas que dificultam a efetividade de práticas avaliativas de perspectiva formativa nas salas de aula são apontadas por Fernandes (2006, p.39): limitações da formação dos professores; dificuldades na gestão do currículo; concepções errôneas dos professores acerca da avaliação formativa; inadequações na organização e funcionamento das escolas; pressões da avaliação externa; e, extensão dos programas escolares.

A pesquisa realizada por Silva e Mendes (2017), na Universidade Federal de Uberlândia, confirma as limitações de compreensão dos professores sobre a avaliação formativa. Os autores consideram que, para promover avanços em direção à melhoria da qualidade do ensino ofertado ou das práticas de avaliação das aprendizagens, "as instituições de ensino superior precisam constituir em seu seio o espaço de formação permanente e desenvolvimento profissional de seus (suas) docentes" (SILVA; MENDES, 2017, p.295).

Buscar alternativas para o desenvolvimento docente implica ações integradas de reflexão e pesquisa sobre o ensino, isto é, promover espaços de discussões e problematizações sobre os dilemas da prática pedagógica. Tal objetivo é consonante com o desenvolvimento de projetos de pesquisa-ação na universidade, o que pode constituir estratégia formativa adequada a este fim. Nesta direção, discutem-se as repercussões do projeto de pesquisa-ação desenvolvido na Universidade Tuiuti do Paraná como estratégia formativa para melhorar as práticas pedagógicas e a avaliação da aprendizagem discente.

\section{A pesquisa-ação na formação pedagógica dos docentes da universidade}

A pesquisa-ação como estratégia metodológica para a formação pedagógica permanente dos professores de diferentes cursos de graduação da Universidade Tuiuti do Paraná (UTP) tem como escopo promover a integração dos participantes no processo de problematização e diálogo 
sobre a prática pedagógica para a intervenção consciente e fundamentada em princípios teóricos da pedagogia crítica emancipatória.

O projeto, criado no ano de 2017, inicialmente reuniu 51 professores interessados em pesquisar e inovar a prática pedagógica com vistas a melhorar a aprendizagem discente. Este número de professores não se manteve fixo, devido à disponibilidade efetiva de participação dos docentes em todo o percurso do projeto de pesquisa-ação. A perspectiva de inovação pedagógica na universidade pretende desencadear um movimento de superação das formas tradicionais e empiristas da docência, baseadas na centralidade da transmissão de informações de característica propedêutica. Segundo Cunha (2016, p. 94), a inovação pedagógica é uma mudança paradigmática que exige dos professores reconfiguração de saberes e o reconhecimento da necessidade de trabalhar no sentido de transformar e gerir relações sociais com seus alunos. Tal ruptura demanda o "reconhecimento de formas alternativas de saberes e experiências, nas quais se imbricam objetividade e subjetividade, senso comum e ciência, teoria e prática, cultura e natureza, anulando dicotomias e procurando gerar novos conhecimentos" (CUNHA, 2016, p. 94).

Nesse sentido, entende-se a relevância de oferecer formação permanente ao professor da educação superior, no que se refere aos conhecimentos científicos de seu campo e do campo da Pedagogia e da Didática. A pesquisa-ação como concepção e método para a formação docente coincide com as linhas de atuação da formação permanente abalizada por Imbernón (2004), que pretende, entre outras ações: a reflexão prático-teórica sobre a própria prática, mediante a análise, a interpretação e a intervenção sobre a realidade; a troca de experiências para atualização e aumento da comunicação entre os docentes em todos os campos da intervenção pedagógica; e o desenvolvimento profissional mediante o trabalho conjunto para transformar a prática, possibilitando a passagem da inovação individual para a institucional (IMBERNÓN, 2004, p. 48).

Entende-se que esta perspectiva de formação pedagógica na educação superior contribui para a superação da racionalidade técnica na ação docente, ainda muito valorizada em propostas de capacitação de professores. Para esta racionalidade, não há necessidade da reflexão, pesquisa e da relação entre teoria e prática, e sim o domínio de procedimentos metodológicos previamente prescritos e planejados, que devem ser executados pelos professores para atingir objetivos de caráter instrutivo informacional.

A pesquisa na ação docente na universidade busca superar aspectos e ações imediatistas da prática pedagógica. Conforme concebem Pimenta e Anastasiou (2005, p. 199), leva à "construção de uma teoria emancipatória: torna os professores mais sujeitos de sua própria 
história profissional, fomentando a concepção e a implementação de novas alternativas diante do desafio que é ser professor universitário".

A perspectiva de aliar ensino e pesquisa se faz congruente com a proposta da "pesquisaação pedagógica por meio da qual os participantes podem desenvolver um estilo de questionamento crítico sobre suas práticas de ensinar e aprender, visando transformá-las." (FRANCO, 2013, p. 12). A partir de suas atividades investigativas junto a docentes, a autora revela que a pesquisa-ação pode funcionar como um instrumento pedagógico para ajudar professores a desbloquear-se da rotina do ambiente profissional e encontrar, no processo investigativo coletivo, a possibilidade para transformações em suas práticas e da própria instituição educacional (FRANCO, 2012, p. 193).

Esclarece Dionne (2007, p. 20) que a pesquisa-ação é considerada um instrumento prático de intervenção antes de ser uma forma de investigação, ou seja, é principalmente um modo de ação antes de ser um método de pesquisa. A pesquisa-ação, em síntese, possui as seguintes características:

É antes de tudo um modo de intervenção coletiva que se insere em um processo de mudança social; É realizada junto a grupos reais e é centrada em uma situação concreta, que constitui problema; Sua duração é a de um projeto de intervenção; Persegue dois objetivos concomitantes: modificar uma dada situação e adquirir novos conhecimentos; Pressupõem-se vínculos estreitos entre pesquisadores e atores; Fortalece o relacionamento entre teoria e prática; Permite gerar conhecimentos novos e originais; tem alcance sociopolítico maior. (DIONNE, 2007, p. 24).

A definição das etapas da pesquisa-ação no projeto de formação de professores da universidade em foco utilizou como referência as orientações metodológicas descritas por Thiollent (1998), as quais foram planejadas abrangendo as seguintes ações:

1. Diagnóstico inicial: identificação dos professores participantes, das disciplinas e turmas, esclarecimento dos objetivos, conhecimento das expectativas dos participantes, discussão sobre questões da prática pedagógica, divisão de tarefas. 2 . Problemática da pesquisa: Designação da problemática a ser investigada. 3. Levantamento de referências bibliográficas que irão compor o marco teórico orientador da pesquisa e será objeto de estudos no coletivo de pesquisa. 4. Construir diretrizes orientadoras da pesquisa. 5. Definição de informações e técnicas que serão utilizadas para a busca de dados. 6. Definição do campo de observação, amostragem e representatividade qualitativa. 7. Registro dos dados em diário de campo e formulários construídos coletivamente (FONTANA; MENDES; PRESTES, 2018, p. $35)$.

Destaca-se no desenvolvimento das etapas da pesquisa-ação a problemática central do projeto: "As inovações pedagógicas em relação às práticas tradicionais promovem melhores aprendizagens e o desenvolvimento de múltiplas competências no processo formativo do estudante?" O desdobramento em outras problematizações relacionadas às inovações pedagógicas foi definido em aderência às singularidades dos professores, suas disciplinas e cursos, desencadeando questões a respeito da relação entre a aprendizagem discente e o uso de 
metodologias ativas, avaliação formativa, projetos interdisciplinares e desenvolvimento da autonomia discente.

As etapas da revisão de literatura para compor o marco teórico referente aos objetos de investigação, como a construção de diretrizes para orientar o percurso da pesquisa, foram fundamentais para a reflexão e acesso ao conhecimento pedagógico, bem como para o desenvolvimento da atitude investigativa dos professores sobre a sua própria prática.

A avaliação do projeto de pesquisa-ação para sua continuidade e (re)planejamento, junto a 12 professores participantes, revelou que a maioria valorizou: o processo de pesquisa coletiva sobre a prática pedagógica; o desenvolvimento da atitude investigativa sobre o ensino e aprendizagem; o conhecimento teórico sobre metodologias ativas. Para metade dos professores, a pesquisa-ação contribuiu para planejar com o coletivo de pesquisadores formas de levantamento e análise de dados e de intervir na situação-problema para obter melhores resultados. Destacam-se algumas expressões dos professores sobre a importância da pesquisaação que coincidem com o seu objetivo:

A atitude investigativa permanente do docente, da sua prática educativa com os estudantes (P1); A relação da pesquisa com a realidade profissional (P10); Poder aplicar as teorias e reaplicar - ou seja - ajustar conforme o andamento das aulas. Essa flexibilidade constante e aprendizado também constante; $\mathrm{O}$ trabalho coletivo dentro da nossa própria prática pedagógica (P12).

Os dados mostram que foi impulsionado um movimento de formação pela pesquisaação, na perspectiva que abaliza Franco (2013, p. 13), que possibilita refletir sobre a prática; discutir com o apoio da teoria; rever e rediscutir os problemas; propor novas práticas; experimentá-las e, a seguir, rever e avaliar para entrar em novo processo de aprendizagem.

Em síntese, a proposta de formação dos professores da UTP, por meio da pesquisa-ação, tem possibilitado a relação entre o ensino e a pesquisa e a formação de um coletivo de professores pesquisadores, integrando professores da graduação e pós-graduação no estudo da pedagogia e didática crítica, na problematização e no planejamento de ações compartilhadas para a resolução de questões da prática pedagógica.

\section{Repercussões da pesquisa-ação na prática de avaliação da aprendizagem}

No desenvolvimento do projeto de pesquisa-ação, a avaliação da aprendizagem como um dos elementos articuladores da prática pedagógica se apresentou como uma problemática de muito interesse para os docentes da UTP, considerando seu impacto na qualidade social da formação dos estudantes. Os problemas apontados pelos professores a respeito da prática avaliativa compreenderam desde questões técnicas de como elaborar estratégias, atividades 
reflexivas e interdisciplinares de avaliação dos conteúdos e competências de aprendizagem, como também questões mais abrangentes quanto à concepção formativa da avaliação e suas finalidades para melhoria da aprendizagem de todos os estudantes.

A problematização sobre as tradicionais práticas avaliativas e a inovação pedagógica para melhorar a aprendizagem discente desencadeou o estudo sobre a concepção de avaliação formativa. O potencial dos métodos ativos e de tecnologias da informação e comunicação foi experimentado e analisado pelos docentes em relação à sua eficácia para construir aprendizagens mais amplas diante das diferentes dimensões dos conteúdos, das características das disciplinas e das múltiplas competências formativas definidas para o perfil do egresso.

Com base na didática crítica, defende Franco (2013, p.14) que as práticas docentes universitárias precisam se utilizar dos fundamentos de métodos ativos, devendo se pautar pelo rigor do conhecimento; pela capacidade de lidar com problemas complexos; pela capacidade de raciocinar criticamente, de argumentar frente a problemas postos, além de desenvolver atitudes de autoconfiança; autodisciplina; capacidade de agir na urgência, a autonomia e criatividade. $\mathrm{O}$ uso de metodologias ativas pelos professores participantes da pesquisa-ação desencadeou novas formas de avaliar a aprendizagem, pois a memorização de conceitos e de técnicas não constitui o foco nestas propostas. Eles confirmam que o desenvolvimento do projeto de pesquisa-ação possibilitou a compreensão teórica para fundamentar novas formas de avaliar, em consonância com a concepção formativa. Quanto às novas práticas avaliativas desencadeadas pelo uso de metodologias ativas e ferramentas tecnológicas, os professores revelam:

\begin{abstract}
A construção do conhecimento por projetos de pesquisa exige avaliação como processo por mediações entre docente, discente, procedimentos didáticometodológicos e conhecimentos. Avalia-se o Projeto de Pesquisa como intervenção metodológica da mesma forma que o produto que é resultante da sua elaboração e aplicação (P1); A avaliação ficou mais fiel à aprendizagem. Faço a avaliação por grelhas que possuem indicadores para cada fase do desenvolvimento do projeto (P10); Utilizo o "Forms" para fazer diversas vezes a auto-avaliação dos alunos, considero esta parte, importante no crescimento deles! (P12).
\end{abstract}

É possível identificar que, para a maioria dos professores, o estudo sobre a avaliação formativa repercutiu mudanças na forma de avaliar e de conceber a avaliação, materializada por eles como uma ação investigativa e diagnóstica. Encontram-se elementos que revelam o planejamento da avaliação e a sua realização em vários momentos do processo de ensino, conforme assim expressam: 
A avaliação tem sido mais frequente e com melhores resultados (P2); Realizo avaliações semanais, em duplas (P7); A avaliação discente está sendo uma avaliação continuada, a cada aula o aluno é avaliado (P9); A avaliação é mais frequente, em diversos momentos, não apenas aquela única avaliação regimental proposta no calendário acadêmico; Também, a proposta da interdisciplinaridade: uma mesma atividade a ser avaliada por dois ou mais professores, ou pela perspectiva de duas ou mais disciplinas (P11).

O estudo teórico sobre a concepção da avaliação formativa repercutiu na visão dos professores participantes da pesquisa-ação, que manifestaram compreensões sobre a centralidade da aprendizagem e a contribuição de estratégias interativas para favorecer as aprendizagens, como expressam:

\begin{abstract}
Me tornei mais crítico em relação a alguns aspectos da avaliação, ela está centrada na aprendizagem do aluno (P8); As avaliações são feitas em sua maioria, em duplas e/ou com consulta. Acredito que deixei de me preocupar com a "cola" entre os alunos. (P5); A avaliação passou a ter maior importância e integrar o processo ensinoaprendizagem. Trabalho com avaliação formativa, ou seja, avaliação do docente, autoavaliação, e as devolutivas de todo o processo avaliativo (P6)
\end{abstract}

Para a maioria dos professores, os principais problemas para desenvolver práticas avaliativas de concepção formativa referem-se, principalmente: ao grande número de alunos nas turmas, o que gera muito tempo para corrigir suas produções e dar o feedback; o perfil do aluno, com muitas dificuldades de leitura e compreensão; o planejamento da avaliação em coerência com os objetivos de ensino e desenvolvimento das competências e habilidades; realizar a avaliação dos conteúdos conceituais, procedimentais e atitudinais; e, realizar avaliações interdisciplinares. Estas dificuldades levantadas por eles são indicativos para continuar a pesquisa-ação e refletir sobre a prática pedagógica em sua totalidade de determinantes, a fim de se encontrarem alternativas para avaliar que garantam níveis satisfatórios de aprendizagem para todos os alunos. Como aduz Libâneo (2018, p. 113), "a avaliação da aprendizagem não é um ato pedagógico isolado, mas sim um ato integrado com todas as outras atividades pedagógicas e a serviço delas".

Em síntese, o espaço de formação permanente desenvolvido por meio do projeto de pesquisa-ação permitiu aos professores da UTP a construção de saberes teórico-práticos para a inovação das práticas de avaliação de concepção formativa, como também o apontamento de problemas que requerem o constante processo de reflexão e investigação coletiva. Estas constatações demandam a continuidade da pesquisa-ação como processo permanente de formação pedagógica na universidade, de intervenção e de construção de conhecimento sobre a prática avaliativa. Assim, a formação de forma individual e coletiva possibilita a pesquisa, a fundamentação teórica e a transformação das práticas. 


\section{Considerações finais}

As reflexões e constatações decorrentes do processo de formação pedagógica pela pesquisa-ação desenvolvido na UTP revelaram avanços significativos, que refletiram novas formas de realizar a avaliação da aprendizagem, principalmente em relação à atitude investigativa dos professores frente ao compromisso com a democratização do conhecimento e com a aprendizagem de todos os alunos.

Não obstante os dados mostrem a perspectiva investigativa e diagnóstica nas práticas de avaliação da aprendizagem, entende-se que é necessário aprofundar a reflexão sobre a seleção dos domínios, ou seja, sobre os conhecimentos que são objetos de ensino e de avaliação, assim como a coerência didática desta relação. Ainda, investigar a qualidade das atividades avaliadas quanto aos progressos e dificuldades cognitivas e metacognitivas dos discentes e como os professores realizam o feedback, considerando a qualidade da realidade observada.

A partir desta constatação, afirma-se que realizar a pesquisa de modo integrado entre professores da graduação e pós-graduação, sobre a prática pedagógica e seus determinantes no espaço da universidade, possibilita a reflexão compartilhada e fortalece a análise crítica acerca dos problemas que envolvem a ação docente e, em especial, em relação à aprendizagem dos estudantes.

Nesta dimensão, a pesquisa qualifica o ensino e este fornece elementos para a construção e reconstrução de teorias e proposições para a resolução de problemas concretos da prática pedagógica. Defende-se a relevância do investimento na formação pedagógica pela pesquisa e para a pesquisa, nas instituições de educação superior, que promovam a compreensão dos contextos e papéis de alunos e professores nos processos de ensino, aprendizagem e da avaliação.

\section{Referências}

BOLDARINE R. de F.; BARBOSA, R. L. L., ANNIBAL, S. F. Tendências da produção de conhecimento em avaliação das aprendizagens no Brasil (2010-2014). Estudos de Avaliação Educacional, São Paulo, v. 28, n. 67, p. 160-189, jan./abr. 2017.

CUNHA, M. I da. Docência na Educação Superior: a professoralidade em construção. Educação, Porto Alegre, v. 41, n. 1, p. 6-11, jan.-abr. 2018.

CUNHA, M. I. da. Inovações na educação superior: impactos na prática pedagógica e nos saberes da docência. Em Aberto, Brasília, v. 29, n. 97, p. 87-101, 2016.

DIONNE, H. A pesquisa-ação para o desenvolvimento local. Brasília: Liber livro, 2007. 
FERNANDES, D. Para uma teoria da avaliação formativa. Revista Portuguesa de Educação, Braga, v. 19, n. 2, p. 21-50, 2006.

FRANCO, M. A. do R. S. Pedagogia e prática docente. São Paulo: Cortez, 2012.

FRANCO, M. A. do R. S. Didática: uma esperança para as dificuldades pedagógicas do ensino superior? In: REUNIÃO NACIONAL DA ANPED, 36., 2013, Goiânia. Anais... Goiânia-GO, 2013.

FONTANA, M. I.; MENDES, J. R.; PRESTES, I. C. P. Formação continuada dos professores da universidade: contribuições da pesquisa-ação para a inovação pedagógica. Revista Tuiuti: Ciência e Cultura, Curitiba, v. 56, n. 5, p. 27-47, 2018.

GARCIA, J. Avaliação e aprendizagem na educação superior. Estudos de Avaliação Educacional, São Paulo, v. 20, n. 43, p. 201-213, maio/ago. 2009.

IMBERNÓN. F. Formação do docente profissional: formar-se para a mudança e a incerteza. 4. ed. São Paulo: Cortez, 2004.

LUCKESI, C. C. Avaliação em educação: questões metodológicas e práticas. São Paulo: Cortez, 2018.

MARCELO, C. Desenvolvimento profissional docente: passado e futuro. Sísifo, Lisboa, v. 8, p. 7-22, 2009.

PIMENTA, S. G.; ANASTASIOU, L. das G. C. Docência no ensino superior. 2. ed. São Paulo: Cortez, 2005.

POLTRONIERI, H.; CALDERÓN, A. I. Avaliação da aprendizagem na educação superior: a produção científica da revista Estudos em Avaliação Educacional em questão. Avaliação, Campinas, v. 20, n. 2, p. 467-487, jul. 2020.

SILVA, N. L.; MENDES, O M. Avaliação formativa no ensino superior: avanços e contradições. Avaliação, Campinas; v. 22, n. 1, p. 271-297, mar. 2017.

THIOLlENT, M. Metodologia da pesquisa-ação. 8. ed. São Paulo: Cortez, 1998.

VEIGA, I. P. A. Docência como atividade profissional. In: VEIGA, I. P. A.; D’AVILA, C. M. (org.). Profissão docente: novos sentidos, novas perspectivas. Campinas: Papirus, 2008.

VEIGA, I. P. A. A docência na Educação Superior e as didáticas especiais: campos em construção. Educação, Santa Maria, v. 36, n. 3, p. 455-464, set./dez. 2011.

ZABALZA, M. A. O ensino universitário: seu cenário e seus protagonistas. Porto Alegre: Artmed, 2004. 